\title{
Self-Mutilation of Genitalia Masquerading as Suicide: A Rare Case Report
}

\author{
Sheikh Shoib ${ }^{* 1}$, Raheel Mushtaq ${ }^{1}$, Tasleem Arif $^{2}$, Wardul Hijaz ${ }^{3}$ \\ ${ }^{1}$ Government Medical College, Srinagar, Kashmir, India, \\ ${ }^{2}$ Dermatologist at the Directorate of health, Jammu and Kashmir, India. \\ ${ }^{3}$ Surgeon at the Directorate of health, Jammu and Kashmir, India.
}

“Corresponding author: Sheikh Shoib, Senior Resident, Department of Psychiatry, Government Medical College, Srinagar, Kashmir, India, Tel: +91 -9797197388, Email: sheikhshoib22@gmail.com

Received date: Feb 3, 2014, Accepted date: March 20, 2014, Published date: April 1, 2014

Copyright: (c) 2014 Sheikh Shoib. This is an open-access article distributed under the terms of the Creative Commons Attribution License, which permits unrestricted use, distribution, and reproduction in any medium, provided the original author and source are credited

\begin{abstract}
Genital self-mutilation is an uncommon, but severe form of self-injury. The causes of self-mutilation of genitalia are multiple that is, from command hallucination in psychotic disorder, drug intoxication, mental retardation, gender dysphasia to personality disorders. Self-mutilation of genitalia as a method of suicide is very rare in depression. Here we report a case of 28 year old male, who presented to emergency department with self-mutilation of genitalia as an attempt of suicide. Thus the clinician should always be watchful while dealing with self-mutilation in psychiatric patients, as sometimes self-mutilation of genitalia in psychiatric patients can present as suicide.
\end{abstract}

Keywords: Depression; personality disorders; Self-mutilation of genitalia; suicide

\section{Introduction}

Self-mutilation is defined as repetitive, deliberate self-destruction of a part of his or her own body that is not life-threatening. Selfmutilation is categorized as a form of self-injury according to some researchers [1]. Self-injury has been defined as a type of self-harm that involves inflicting injury or pain on one's own body. Various forms of self-injurious behavior include cutting with sharp objects, pulling out finger and toe nails, pin pricks, skin picking, head banging and other injurious behavior [2]. Minor self-mutilation is fairly common in general population and does not cause any infirmity, as it is usually part of cultural practice. Major Self-Mutilation (MSM) is a very rare complication of severe mental illness and causes significant disability [3].Ocular, genital, and limb mutilation are the three main forms of major self-mutilation. The estimated incidence of self-mutilation in adolescents and young adults is 1,800 per 100,000[3]. However incidence among inpatient adolescents is $40 \%$ [4]. The incidence of severe forms of major self-mutilation is very rare ( 1 in 4,000,000 per annum). Further, $4 \%$ of hospitalized psychiatric patients have history of attempt of self-mutilation [5]. 55\%-85\% of self-mutilators have attempted suicide, at least one in their life [4].

Although suicide and self-mutilation appear to possess the same goal of pain relief, but the respective desired outcomes of each of these behaviors is not entirely similar [6]. Suicide has been defined as selfinflicted death with evidence that the person intends to die. The various scales used for assessing suicidal ideation are Scale for Suicide Ideation (SSI), scale for suicide Ideation - (Worst), Beck Scale for suicide Ideation, and modified scale for suicide Ideation [7].

Self-mutilation is common in psychiatric disorder and occurs due to various reasons. The various causes of self-mutilation are psychotic, non-psychotic illness and various organic and functional syndromes. Psychotic illness includes command hallucinations in schizophrenias patients, bipolar affective disorder with psychotic features and borderline personality disorder [5]. Gender dysphoria, male identification, guilt for sexual offences, sexual conflicts and offences, erotic purposes and body image preoccupation are the other psychopathologies proposed for genital self-mutilation in nonpsychotic illnesses [8].Various syndromes like Lesch-Nyhan syndrome, Cornelia de Lange syndrome and syndromes associated with mental retardation are the other important causes of selfmutilation [9].The rare causes of genitalia self-mutilation are cannabis and cocaine abuse, alcohol intoxication, and amphetamine use $[8,10]$. Combined mutilation of both penis and scrotum has been reported in patients with command hallucinations and religious delusions [4]. However combined mutilation of both penis and scrotum is quite rarely reported in patients of depression. Khandelwal et al. [11] and Rao et al. [8] have reported cases of genital mutilation in elderly patient suffering from depression. Raoet al. [8] reported a case genital self-mutilation in elderly patients suffering from major-Depressive Disorder with psychosocial factors. Similarly Khandelwal et al. [11] described auto castration in patient suffering from depression with psychosocial stressors. Here we report a 28 year old male suffering from major depressive disorder without any psychosocial stressors, who presents to us with self-mutilation of genitalia as an attempt of suicide. The authors are of the view, that this case is the first of its kind reported in the literature, where a young male suffering from major depressive disorder without any psychosocial stressors, presented with self-mutilation of genitalia as an attempt to suicide.

\section{Case Presentation}

year old Kashmiri male, Muslim, right handed, presented to emergency department with

profuse bleeding from the genitalia. Patient had self-mutilated his genitalia with a razor blade. In the emergency department, the patient was bleeding profusely from the genitalia and his clothes and body parts were soaked with blood. The patient looked bewildered and fearful and was screaming with pain. He kept weeping and demanding for poison to kill himself at the time of admission in emergency department. Patient developed hypovolemic shock due to severe 
bleeding. The patient was then stabilized in the emergency department for a week. After resuscitation of patient and stabilization of vital signs, a surgery consultation was sought and was admitted in the surgery department. The patent later underwent perineal urethrostomy and orchiectomy. After one week in surgery department, patient was advised psychiatric check-up in view of persistent suicidal ideation. History of psychiatric illness was asked from the attendants and they revealed that patient was working in a factory as a mechanic quite regularly six month ago. However over the last few months, he became quite irregular in his work. Further attendants reported that patient had history of low mood with decreased interest in work, disturbed sleep, and decreased interaction with family members for the last 6 months. Detailed history from the patient revealed low mood, anhedonia, decreased self-care and biological functions for a period of 6 months. He reported persistent and pervasive low mood with suicidal ideation for the last 6 months, apparently, due to unknown reasons. Patient was asked why he mutilated his genitalia. Patient rebuked and said "that genitals are very essential organs and by amputating them, he wanted to die immediately". There was no history suggestive of delusions or hallucinations. There was no history of alcohol consumption, smoking or any other substance abuse. There was no history suggestive of gender dysphoria, male identification, and body image disturbance, guilt for sexual offences, sexual conflicts, erotic purposes and body image preoccupation. His parents were not related to each other. None of his near relatives suffered from epilepsy or any obvious behavioral problems. There was no family history of present or past psychiatric illness or mental retardation. The patient is third of four siblings born to non-consanguineous parents. He was born full term and had a normal delivery. Child hood history was nonsignificant. Premorbidly he was reserved, had quite good number of friends. He was well mixing honest, and hardworking.

\section{Physical examination}

Physical examination revealed no icterus, Kayser Fleischer rings, goitre, hepatomegaly, and lump in the abdomen or signs of tetany. Figures 1 and 2 shows the amputated site of penis and lacerated scrotum with testis on surface.

\section{Extended mental status}

Examination revealed a well groomed but somewhat perplexed individual. Took time to respond, talked slowly and persevered. He reported subjective sadness and looked depressed. Thinking was retarded but connected, with suicidal ideation, feeling of worthlessness and hopelessness. Attention/concentration was intact, well orientation and good fund of general knowledge with grade 4 insight. There was no sensory or motor deficit. Physical and neurological examination was normal.

\section{Investigations}

Haematological and biochemical parameters were within normal range. His ultrasonography of abdomen (USG), ophthalmic examination, and brain CT scan (Computerized scanning) were normal.

\section{Neuropsychological evaluation}

Performance intelligence 71 and verbal quotient 92.

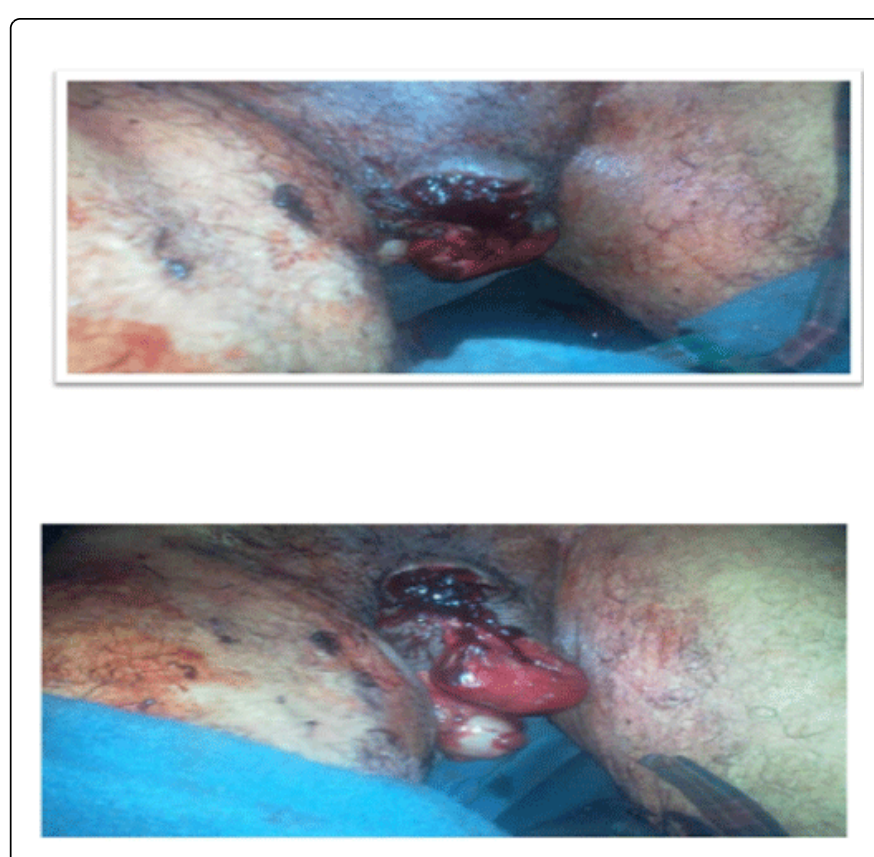

Figure1. The amputated site of penis, Figure 2. Lacerated scrotum with testis on surface

\section{Treatment and follow-up}

He was diagnosed as major depressive disorder, as per the Diagnostic and Statistical Manual of Mental Disorders 4th edition (DSM Iv). At the time of admission, Montgomery-Asberg Depression Rating Scale (MADRS) score was 42 and Suicide Ideation score (Beck Suicide Ideation Scale) was 29. He was started with mirtazapine $15 \mathrm{mg}$ daily bed time. At the time of discharge Beck Scale for Suicide Ideation dropped significantly to 11 and MADRS decreased to 19 respectively. Patient was discharged from the hospital after 3 weeks and was maintained on mirtazapine $15 \mathrm{mg}$ bed time daily. He came to the psychiatry department after 3 months for follow up. He reported no sadness and resumed his previous work. The improvement was seen as a response to treatment. Three months after initial evaluation, he was pleased with the response of the pharmacotherapy with MADRS score 11 and Suicide Ideation score (Beck Suicide Ideation Scale) of 8.After 4 months MADRS score dropped to 5, suggestive of remission.

\section{Discussion}

Genital self-mutilation was first reported by Storch [12]. Psychotic disorders are the most common causes of severe and isolated form of self-injurious behavior [13]. Schizophrenia, secondary to delusions and hallucinations cause self-injurious behavior most cases of genital self-mutilation reported in the literature have been in psychotic patients with either functional or organic brain disease $[5,14]$. Our case is an unusual type of genital self-mutilation in patient suffering from depression without any psychotic features $[8,10]$. Here in, we report a case of 28 year old male patients suffering from major depressive disorder without psychotic features from the last six month, who presented to us with self-mutilation of genitalia (penis, with both testes and scrotum). The patient was suffering from major depressive disorder without psychotic features for last 6 months and made an 
Page 3 of 3

attempt of suicide by genitalial mutilation. Patients belonged to rural area of Kashmir (India) and was an illiterate. It is a notion in rural areas of Kashmir (India) that genitalia are vital organs and mutilating them will lead to death. In Indian settings, cases of severe mutilation in response to religious delusions and self-induced bleeding to relieve pain in cases of delusional disorders have been reported. Our case however had no association with any religious or sexual theme [15]. In this case, the self-mutilation was attributed as an act of suicide. On rare occasions self-mutilation of genitalia has been reported in nonpsychotic disorders too [16].

However, self-mutilation in response to eroticism, body image disturbance, expression of internalized aggression and suicidal intent has been reported earlier [13]. In this case, there was no evidence of hallucinations, delusions, body image disturbance or sexual conflicts. In the present case there was also no history suggestive of gender dysphoria, male identification, guilt for sexual offences, sexual conflicts and offences, erotic purposes and body image preoccupation. However there was an indirect evidence of frustration, leading to internalized aggression and resulting in an impulsive suicidal attempt. There are a few cases of genital mutilation in elderly patients suffering from depression with psychosocial stressors $[8,11]$. In contrast, our patient was a young male, with one episode of major depressive disorder without psychotic features and no psychosocial stressors. Maclean and Robertson (1976) reported that self-injurious behaviors associated with castration anxiety and elucidated a process of failure to resolve oedipal complex, self-punishment in depression with inner aggression leading to suicide [17]. Onset of puberty is associated with revival of oedipal issue. Sexual fantasies about mother along with aggressive impulses are experienced as overwhelming. Self-mutilators may thus feel forced by their bodies to have these fantasies and selfmutilation is therefore an attempt to destroy the body, which is seen as separate from self. Others researchers have suggested that interpersonal loss, preceding self-injurious behavior, connected to rejection sensitivity as causes of self-mutilation [18]. Our patient had Major Depressive Disorder who developed inner aggression and selfpunishment, leading to genital mutilation. The risk factors in selfinjury syndrome include biological, behavioural, cultural and psychodynamic factors. These risk factors should be identified and the underlying disorders managed at the earliest. Our Patient was started mirtazapine $15 \mathrm{mg}$ daily bed time and was discharged from the hospital after 3 weeks and maintained on mirtazapine $15 \mathrm{mg}$ bed time daily. Beck Scale for Suicide Ideation dropped significantly from admission to discharge respectively 29 to 11.3 months after initial evaluation; he was pleased with the response of the pharmacotherapy with MADRS Montgomery-Asberg Depression Rating Scale score11.After 4 months MADRS score dropped to 5, suggestive of remission.

Finally it is important to mention that genital self-mutilation can occur in any psychiatric condition with its own distinct psychopathology and should be viewed as constellation of disorder [14]. The patients with history of self-mutilation should be hospitalized immediately and medical, surgical and psychiatric consultation should be sought at the earliest. The outcome of these patients depends on the integrated collaborative work. Genital self mutilation is rare in this part of world (Kashmir, India). So Psychiatrist and urologist should be watchful in every case of genital self - mutilation and employ the integrated effective management for these cases.

\section{References}

1. Favazza A (1987) Bodies Under Siege. Baltimore: John Hopkins University Press.

2. Favaro A, Santonastaso P (2000) Self-injurious behaviour in anorexia nervosa. JNervMent Dis 188: 537-542.

3. Large M, Babidge N, Andrews D, Storey P, Nielssen O(2009) Major selfmutilation in the first episode of psychosis. Schizophr Bull13:1012-1021.

4. Suyemoto KL, MacDonald ML (1999) Self-cutting in female adolescents. Psychotherapy 32: 162-171.

5. Kaplan HI, Sadock BJ (2000) Comprehensive textbook of psychiatry; volume 1, P: 817. Editor:Sadock V.A, 7th Ed, New York.

6. Stanley B, Gameroff MJ, Michalsen V, Mann JJ (2001) Are suicide attempters who self-mutilate a unique population? Am J Psychiatry 158: 427-432.

7. Brown G KA (2000) review of suicide assessment for intervention research with adults and older adults (Technical report submitted to NIMH under contract No.263-MH914950) Bethesda MDNational institute of Mental health.

8. Rao KN, Bharathi G, Chate S (2002) Genital self-mutilation in depression: a case report. Indian J Psychiatry44:297-300.

9. Kaplan HI, Sadock BJ (1791) Synopsis of psychiatry, 8th Ed; Courtney Milet; 1998; New Yorkp: 869-870.

10. AhsainM,Tazif F, Khalouk A et al (2011) Bilateral testicular selfcastration due to cannabis abuse: a case report. J Medical Case Reports 5:404.

11. Khandelwal SK, Verma VK, Gupta R (1981) Auto castration: Review with case report.Indian J Psychological Medicine 4:119-121.

12. Stroch D (1901) Self-castration. Letter to the editor. JAMA 36:270.

13. Greilsheimer H, Graves JE (1979) Male genital self-mutilation. Arch Gen Psychiatry 36:441-446.

14. Martin T, Gattaz WF (1991) Psychiatric aspects of male genital selfmutilation.Psychopathology 24:170-178.

15. Rao KN, Begum S, Chate S (2003) Genital Self- Mutilation in Mental Retardation. The NADD Bulletin 6:38-40.

16. Wan SP, Soderdahl DU, Blight EM (1985) Nonpsychotic genital selfmutilation.Urology 26: 286-287.

17. Maclean G, Robertson BM (1976) Self enucleation and psychosis. ArcGen Psychiatry 33: 242.

18. Liebowitz MR, Klein DF (1979) Hysteroiddysphoria. Psychiatric Clinics ofNorth

America2:555-575 